\title{
Identification of candidate substrates for ectodomain shedding by the metalloprotease-disintegrin ADAM8
}

\author{
Silvia Naus', Simone Reipschläger', Dirk \\ Wildeboer ${ }^{1, a}$, Stefan F. Lichtenthaler ${ }^{2}$, Stefan \\ Mitterreiter', Ziqiang Guan ${ }^{3}$, Marcia L. Moss ${ }^{4}$ \\ and Jörg W. Bartsch ${ }^{1, a, *}$
}

${ }^{1}$ Entwicklungsbiologie und Molekulare Pathologie, W7, Universität Bielefeld, D-33615 Bielefeld, Germany

${ }^{2}$ Adolf-Butenandt-Institut, Ludwig-Maximilians-

Universität, Schillerstr. 44, D-80336 München, Germany

${ }^{3}$ Department of Biochemistry, Duke University Medical

Centre, Durham, NC 27710, USA

${ }^{4}$ BioZyme Inc., 1513 Old White Oak Church Road, Apex, NC 27523, USA

${ }^{*}$ Corresponding author

e-mail: jorg.bartsch@kcl.ac.uk

\begin{abstract}
ADAM proteases are type I transmembrane proteins with extracellular metalloprotease domains. As for most ADAM family members, ADAM8 (CD156a, MS2) is involved in ectodomain shedding of membrane proteins and is linked to inflammation and neurodegeneration. To identify potential substrates released under these pathologic conditions, we screened 10-mer peptides representing amino acid sequences from extracellular domains of various membrane proteins using the ProteaseSpot ${ }^{\mathrm{TM}}$ system. A soluble ADAM8 protease containing a pro- and metalloprotease domain was expressed in E. coli and purified as active protease owing to autocatalytic prodomain removal. From 34 peptides tested in the peptide cleavage assay, significant cleavage by soluble ADAM8 was observed for 14 peptides representing membrane proteins with functions in inflammation and neurodegeneration, among them the $\beta$-amyloid precursor protein (APP). The in vivo relevance of the ProteaseSpot ${ }^{\mathrm{TM}}$ method was confirmed by cleavage of full-length APP with ADAM8 in human embryonic kidney 293 cells expressing tagged APP. ADAM8 cleaved APP with similar efficiency as ADAM10, whereas the inactive ADAM8 mutant did not. Exchanging amino acids at defined positions in the cleavage sequence of myelin basic protein (MBP) revealed sequence criteria for ADAM8 cleavage. Taken together, the results allowed us to identify novel candidate substrates that could be cleaved by ADAM8 in vivo under pathologic conditions.
\end{abstract}

Keywords: ADAM protease; candidate substrates; ectodomain shedding; fluorescence assay; peptide cleavage.

aPresent address: Department of Biochemistry, King's College London, London SE1 9NH, UK

\section{Introduction}

ADAMs (a disintegrin and metalloprotease) or MDCs (metalloprotease disintegrin cysteine-rich proteins) form a family of type I transmembrane proteins. Owing to their multidomain structure consisting of pro-, metalloprotease, disintegrin-like, cystein-rich, EGF-like, transmembrane and cytoplasmic domains, ADAMs are capable of four physiological functions: cell adhesion, cell fusion, cell signalling and proteolysis.

They are implicated in physiological processes such as fertilisation, myogenesis and neurogenesis, and are also involved in a number of pathological processes by releasing cytokines and their receptors under inflammatory conditions (Moss and Bartsch, 2004). To date, 40 members are known in different species (table of ADAMs on http://www.people.virginia.edu/ jw7g/). Approximately half of these ADAMs contain the catalytic consensus sequence HEXXHHXXGXXHD in their metalloprotease domains and are therefore predicted to be catalytically active. Proteolysis of membrane-anchored precursor proteins is a key event in signalling cascades (Blobel, 2005) and this process has been termed ectodomain shedding (Peschon et al., 1998). A number of ADAM substrates have been defined either by their physiological role or by their cellular localisation (Seals and Courtneidge, 2003; Moss and Bartsch, 2004; Blobel, 2005). So far, no consensus sequence on the substrate side has been reported, making prediction of potential cleavage sites difficult. Rather, ADAMs recognise a structural footprint on the extracellular part of the membrane protein, and it is assumed that cleavage occurs in the juxtamembraneous regions of these membrane proteins.

Our particular research interest is the ADAM family member ADAM8, originally identified as MS2 or CD156 in mouse macrophages (Yoshida et al., 1990). ADAM8 is expressed in several tissues, such as thymus, cartilage, bone, brain and spinal cord, during embryonic development. As embryonic development of the ADAM8-deficient mouse appears normal, ADAM8 does not seem to be essential for developmental processes (Kelly et al., 2005). Rather, it is more likely that ADAM8 has a specific function in cytokine response. In response to inflammatory stimuli such as lipopolysaccharide (LPS) and tumour necrosis factor $\alpha$ (TNF- $\alpha)$, ADAM8 expression is upregulated in macrophages and in the central nervous system (CNS) in activated glia cells - astrocytes and microglia - indicating its involvement in neuron-glia signalling (Schlomann et al., 2000). In addition to glial cells, ADAM8 is expressed in neurons at low levels, and expression is induced by TNF- $\alpha$, suggesting that under inflammatory conditions in the CNS, neuronal ADAM8 activity is significantly increased (Schlomann et al., 2000).

In the lung, ADAM8 is upregulated under experimental induction of allergic asthma by inflammatory cytokines 
(King et al., 2004), suggesting that ADAM8 plays a role in the pathogenesis of allergic asthma. All these findings underline the importance of ADAM8 in inflammatory processes.

Recent attention has focussed on ADAM8 as a molecule upregulated in various tumours. ADAM8 is considered a prognostic marker for lung adenocarcinomas (Ishikawa et al., 2004) and renal cell carcinomas (Roemer et al., 2004). In addition, in brain tumours such as glioblastoma, oligoastrocytoma, and ependymoma, ADAM8 expression was increased compared to normal brain controls, and ADAM8 expression in glioblastoma correlates with malignancy and invasive activity (Wildeboer et al., unpublished results). In B-cells, ADAM8 cleaves the low-affinity lgE receptor (CD23, FceRII) suggesting a role in immune modulation (Fourie et al., 2003). Although ADAM8 seems to impair allergy and inflammation by ectodomain shedding, only a few substrates of ADAM8 and their corresponding cleavage sites are known (Amour et al., 2000; Schlomann et al., 2002; Fourie et al., 2003; Naus et al., 2004). In the present study, we analysed the ability of ADAM8 to cleave 10-mer peptides as representatives of the extracellular domains of membrane proteins involved in immune modulation, inflammation, and cell adhesion.

\section{Results}

\section{Expression and purification of active ADAM8 protease from $E$. coli}

The bacterial expression vector pASK-IBA3+ allows for expression of recombinant ADAM8 pro-/metalloprotease (A8ProMP) in the cytoplasma after induction with anhydrotetracycline (aTc). Maximal expression rates were obtained 4-6 h after aTc induction and decreased after overnight induction, probably owing to instability of the protein (Figure 1A). Expression of A8ProMP is reflected by a band of ca. $56 \mathrm{kDa}$, while a lower band of ca. $33 \mathrm{kDa}$ represents the entire metalloprotease domain of ADAM8 (A8MP) after prodomain removal.

Approximately two-thirds of the total ADAM8 protein expressed in $E$. coli was found in inclusion bodies, and one-third in the cytoplasmic fraction. This fraction was taken for further purification using Strep-Tactin ${ }^{\circledR}$ columns (Figure 1B) without any additional treatment to increase ADAM8 solubility. After elution from the column, one fraction was collected that contained most of the ADAM8 protein (Figure 1B, C). This fraction contained a significant amount of processed ADAM8, as monitored by Western blotting (Figure 1B) and SDS-PAGE (Figure 1C), and was used in all further studies.

\section{Activity of the recombinant ADAM8 protease}

The catalytic activity of recombinant A8MP was tested using a peptide derived from the cleavage sequence of human CD23 (DNP-SHHGDQMAQKSQSTQI) in a fluorescamine assay (Figure 2). Within $4 \mathrm{~h}$ of incubation, there was significant cleavage of the CD23 peptide, whereas no cleavage was observed in the controls, including a sample with ADAM8 protease in the presence of EDTA.
A

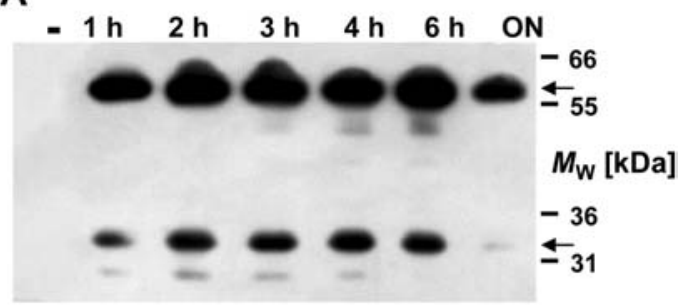

B

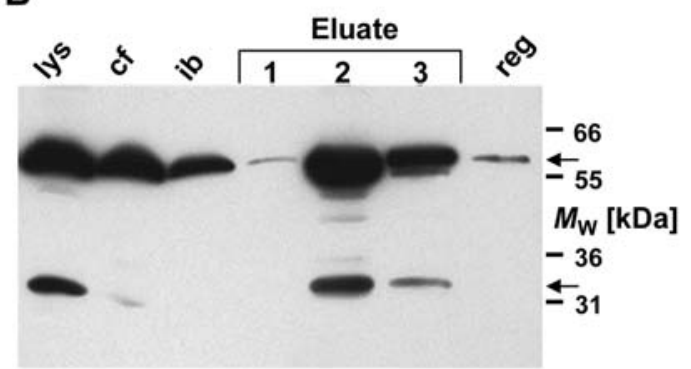

C

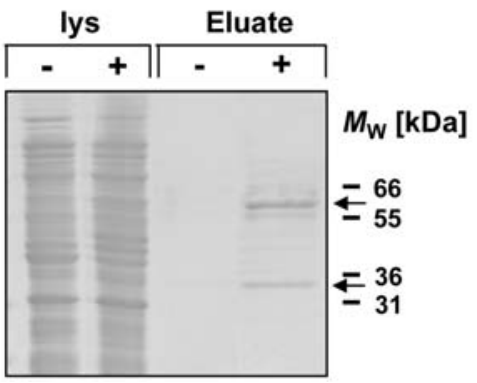

Figure 1 Expression of soluble ADAM8 protease in E. coli. (A) Time course of recombinant ADAM8 induction; times are given in $\mathrm{h}$ after addition of anhydrotetracycline (aTc) into the medium. Overnight induction ('ON') caused a decrease in the amount of recombinant protein, whereas '-' indicates no induction. (B) Purification of recombinant ADAM8 from $E$. coli; lys, total bacterial lysate; cf, cytoplasmic fraction; ib, inclusion bodies; 1, 2, and 3 are different elution fractions after Strep-tag ${ }^{\circledR}$ affinity chromatography; reg, regenerate. Both blots were stained for ADAM8 using a monoclonal anti-BiPro-tag antibody. The upper band (ca. $56 \mathrm{kDa}$ ) indicated by an arrow corresponds to the proform of soluble ADAM8 protease, containing the pro- and metalloprotease domain; the lower band (ca. $33 \mathrm{kDa}$ ) matches with the metalloprotease domain after prodomain removal. (C) Coomassie Blue-stained SDS-PAGE with total bacterial lysates (lys) and Strep-tag ${ }^{\circledR}$ affinity chromatography eluates (eluate) from uninduced (-) and aTc-induced $(+) E$. coli.

A8ProMP isolated from $E$. coli was not active, demonstrating that only the entire MP domain confers proteolytic activity (data not shown).

Cleaved peptides were separated by HPLC and subjected to mass spectrometry. The CD23 cleavage site is located between a glutamine and lysine residue: QMAQ $\downarrow K S Q$ (see also Table 1).

\section{ADAM8 peptide substrates}

Our focus was to characterise the role of catalytically active ADAM8 in (neuro-) inflammation. A total of 34 peptides derived from proteins involved in inflammatory processes and immune response in the nervous system were selected. In most cases they represent membraneproximal sequences. 


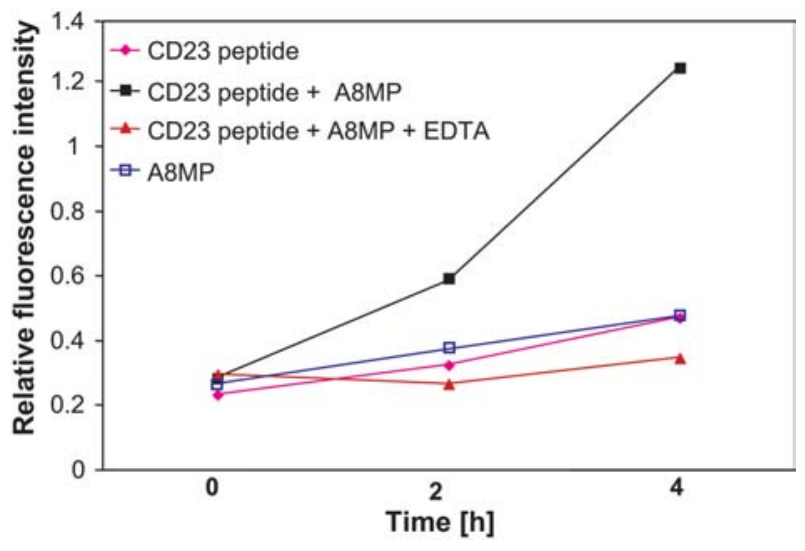

Figure 2 Fluorescence determination of ADAM8 activity using the CD23 peptide DNP-SHHGDQMAQKSQSTQI.

Relative fluorescence intensities were determined initially $(t=0)$, and after 2 and $4 \mathrm{~h}$ by addition of fluorescamine. As controls, CD23 peptide alone, A8MP alone, or CD23 peptide mixed with A8MP in the presence of 10 mM EDTA was incubated under reaction conditions. The peptide assay was repeated at least five times and the values given are representative of all experiments performed.

All peptides, with the corresponding proteins and their accession numbers in the Swiss-Prot/TrEMBL protein database, are listed in Table 1.

Cleavage assays were performed with A8MP in the absence or presence of $10 \mathrm{~mm}$ EDTA. Fluorescence increases were monitored over $18 \mathrm{~h}$. In cases of consistent and significant fluorescence increase and no response in the presence of EDTA, ADAM8-specific cleavage was concluded.

The relative fluorescence increase corresponding to cleavage efficiency was expressed as relative units and was normalised to the MBP peptide as 1 (Figure 3A). Relative fluorescence increases of $1 \mathrm{U}$ and higher were considered as significant ADAM8-specific cleavage. Fluorescence increases between 0.5 and $1 \mathrm{U}$ indicate cleavage, although at lower levels, given the fact that significantly cleavable peptides incubated with A8MP in the presence of EDTA never exceeded $0.3 \mathrm{U}$. In addition, the time dependence of cleavage was monitored for two selected peptides (APP and CD23.1; Figure 3B). With these peptides, a clear correlation between the incubation time and the increase in relative fluorescence intensity was demonstrated.

Summarising the results of the peptide screen, 14 of 34 tested peptides were cleaved by ADAM8, 10 of them strongly and four to a lesser extent. Among the strongly cleaved peptides were those derived from $\beta$-amyloid precursor protein (APP), low-affinity IgG receptor (CD16, Fc $\gamma$-RIII), low-affinity IgE receptor (CD23, FceRII), fractalkine CX3CL1, L-selectin, P-selectin glycoprotein ligand (PSGL-1), transforming growth factor $\alpha$ (TGF- $\alpha$ ) and TNF- $\alpha$. Furthermore, peptides derived from macrophage haemoglobin scavenger receptor (CD163), interleukin-1 receptor type II (IL-1-RII), TNF receptor 1 (TNFRI) and TNF-related activation-induced cytokine (TRANCE) were cleaved with lower efficiency. In contrast to data published by Amour et al. (2002), a peptide derived from kit ligand (KL) was not cleaved.

For PSGL-1 and CD23, two peptides were cleaved. The two peptides for PSGL-1 shared overlapping amino acids, suggesting that a cleavage site might be located in this overlapping region, which contains the amino acids KKG. A similar cleavage site was observed for the TGF- $\alpha$ peptide, which is cleaved at SQ $\downarrow$ KK and SQK $\downarrow$ K. CD23 is known to be released from the cell surface by cleavage at three different cleavage sites (Mayer et al., 2002). ADAM8 cleaves at two of these sites in the two corresponding peptides. Both of these peptides also contain glutamine residues, underlining a certain preference for amino acid residues.

\section{ADAM8 cleavage of MBP peptide variants}

A 10-mer peptide derived from MBP is cleaved by recombinant ADAM8 (Schlomann et al., 2002). To identify specific amino acid requirements necessary for substrate cleavage, peptide cleavage assays with various peptides derived from the MBP cleavage site were performed using the ProteaseSpot ${ }^{\mathrm{TM}}$ system. Assays were performed in the absence or presence of $10 \mathrm{~mm}$ EDTA (Figure 4). The fluorescence increase corresponding to protease activity was monitored over $18 \mathrm{~h}$. The fluorescence increase was expressed in units normalised to the original bovine MBP peptide $(=1)$. According to variable fluorescence increases, it was concluded that ADAM8 cleaved the MBP peptide variants with different efficiencies, depending on the amino acid exchange. The peptides bearing exchange of leucine for serine at position P3 (peptide 2), of threonine for alanine at position P3' (peptide 8) and basic residues - arginine or lysine - for a proline at position P1 (peptides 3 and 4) were cleaved by ADAM8. Possibly, there was slightly enhanced cleavage for the variants with basic amino acids in position P1 compared to the original MBP peptide. Amino acid exchanges at positions $\mathrm{P} 1$ ' and $\mathrm{P} 2$ ' had significant effects on peptide cleavage (peptides 5-7). Exchange of a glutamine residue to an acidic glutamic acid residue in position $\mathrm{P}^{\prime}$, as well as exchange of the basic lysine residue in position $\mathrm{P} 2^{\prime}$ to either an acidic (glutamic acid) or a neutral, aliphatic amino acid (valine) resulted in decreased levels of peptide cleavage.

From these results, we conclude that basic residues in positions $\mathrm{P} 1$ and $\mathrm{P} 2$ ' increase the efficiency of ADAM8 cleavage, whereas acidic residues in position $\mathrm{P} 1^{\prime}$ and $\mathrm{P} 2{ }^{\prime}$ decrease cleavage.

\section{ADAM8-dependent cleavage of APP in human embryonic kidney 293 cells}

We tested whether transfection of ADAM8 into human embryonic kidney 293 cells increased secretion of membrane-associated APP in a cell-based assay. Human 293 cells were used that stably express a fusion protein consisting of the reporter enzyme alkaline phosphatase (AP) tagged to the N-terminus of full-length APP (AP-APP cells). Upon shedding of the APP ectodomain, the soluble AP-tagged APP can easily be detected by measuring the AP activity in the conditioned medium (Lichtenthaler et al., 2003; Schöbel et al., 2006). The APAPP cells were transfected with constructs encoding ADAM8 and inactive EQ-ADAM8, bearing a point mutation by which glutamate residue 330 is exchanged to a glutamine (Schlomann et al., 2002). This mutant form of 
Table 1 List of peptides and sequences used for screening ADAM8 candidate substrates.

\begin{tabular}{|c|c|c|c|}
\hline Protein & Peptide substrates & ADAMs involved & References \\
\hline $\begin{array}{l}\text { APP } \\
\beta \text {-Amyloid precursor protein } \\
\text { Accession no. } \mathrm{P} 12023\end{array}$ & EVRH $\downarrow Q K L V F F$ & ADAM8, 9, 10, 17, 33 & $\begin{array}{l}\text { Amour et al., } 2002 \\
\text { Buxbaum et al., } 1998 \\
\text { Koike et al., } 1999 \\
\text { Mohan et al., } 2002 \\
\text { Zou et al., } 2004\end{array}$ \\
\hline $\begin{array}{l}\text { CD16 } \\
\text { Fce-RIII, low-affinity lgG receptor } \\
\text { Accession no. P08508 }\end{array}$ & $\begin{array}{l}\text { SLVWYHTAFS } \\
\text { PATTSSISLV } \\
\text { VTITVQDPAT } \\
\text { TQHQ } \downarrow \text { SKPVTI }\end{array}$ & MP & Harrison et al., 1991 \\
\hline $\begin{array}{l}\text { CD23 } \\
\text { FC } \varepsilon \text {-RII, low-affinity IgE receptor } \\
\text { Accession no. P20693 }\end{array}$ & $\begin{array}{l}\text { SNQLAQ } \downarrow K \downarrow S Q V \\
\text { AEQKQMKAQD } \\
\text { LRNAQSQ } \downarrow N S K \\
\text { VAKLWIEILI }\end{array}$ & MP, ADAM8 & $\begin{array}{l}\text { Fourie et al., } 2003 \\
\text { Marolewski et al., } 1998 \\
\text { Mayer et al., } 2002\end{array}$ \\
\hline $\begin{array}{l}\text { CD40-L } \\
\text { Accession no. P27548 }\end{array}$ & NSFEMQRGDE & ADAM10 & Amour et al., 2002 \\
\hline CD163 & HGTGHP $\downarrow$ TLTA & & \\
\hline $\begin{array}{l}\text { Macrophage haemoglobin scavenger } \\
\text { receptor }\end{array}$ & $\begin{array}{l}\text { PKMTSESHGT } \\
\text { DASIQCLPKM }\end{array}$ & & \\
\hline Accession no. AAK16065 & $\begin{array}{l}\text { SDCGHKEDAS } \\
\text { PAKPWSHSDC } \\
\text { ESSLWDCPAK }\end{array}$ & MP & Droste et al., 1999 \\
\hline $\begin{array}{l}\text { Fractalkine CX3CL1 } \\
\text { Accession no. O35188 }\end{array}$ & QAATRR $\downarrow$ QAVG & ADAM17 & Garton et al., 2001 \\
\hline $\begin{array}{l}\text { IL-1-RII } \\
\text { Interleukin-1 receptor type II } \\
\text { Accession no. P27931 }\end{array}$ & TTVKEVS $\downarrow S_{\text {STF }}^{a}$ & ADAM8, 17 & $\begin{array}{l}\text { Amour et al., } 2002 \\
\text { Reddy et al., } 2000\end{array}$ \\
\hline $\begin{array}{l}\text { KL } \\
\text { Kit ligand } \\
\text { Accession no. P20826 }\end{array}$ & PPVAASSLRN & ADAM8, 9, 17, 33 & $\begin{array}{l}\text { Amour et al., } 2002 \\
\text { Chesneau et al., } 2003 \\
\text { Mohan et al., } 2002 \\
\text { Roghani et al., } 1999 \\
\text { Zou et al., } 2004\end{array}$ \\
\hline $\begin{array}{l}\text { L-Selectin } \\
\text { Accession no. P18337 }\end{array}$ & QETNRS $\downarrow$ FSKI & ADAM17 & Peschon et al., 1998 \\
\hline $\begin{array}{l}\text { MBP } \\
\text { Myelin basic protein } \\
\text { Accession no. P04370 }\end{array}$ & YGSLP $\downarrow Q K A Q G^{b}$ & ADAM8, 10, 28 & $\begin{array}{l}\text { Chantry et al., } 1989 \\
\text { Howard et al., } 2001 \\
\text { Schlomann et al., } 2002\end{array}$ \\
\hline $\begin{array}{l}\text { PSGL-1 } \\
\text { P-Selectin glycoprotein ligand } 1 \\
\text { Accession no. Q62170 }\end{array}$ & $\begin{array}{l}\text { LIPVKQCLLI } \\
\text { TLPGSSDLIP } \\
\text { PGNSPAPTLP } \\
\text { K } \downarrow \text { K } \downarrow \text { GLIVTPGN } \\
\text { HLPDSGLK } \downarrow \downarrow G^{c}\end{array}$ & MP & Davenpeck et al., 2000 \\
\hline $\begin{array}{l}\text { TGF- } \alpha \\
\text { Transforming growth factor } \alpha \\
\text { Accession no. P48030 }\end{array}$ & $\begin{array}{l}\text { ADLLAVVAAS } \\
\text { AVVAASQ } \downarrow K \downarrow K Q\end{array}$ & MP, ADAM17 & $\begin{array}{l}\text { Arribas et al., } 1997 \\
\text { Peschon et al., } 1998\end{array}$ \\
\hline $\begin{array}{l}\text { TNF- } \alpha \\
\text { Tumour necrosis factor } \alpha \\
\text { Accession no. P06804 }\end{array}$ & A $\downarrow Q T L T L R S \downarrow S S$ & ADAM8, 9, 10, 17, 19 & $\begin{array}{l}\text { Amour et al., } 2002 \\
\text { Black et al., } 1997 \\
\text { Chesneau et al., } 2003 \\
\text { Mohan et al., } 2002 \\
\text { Moss et al., } 1997\end{array}$ \\
\hline $\begin{array}{l}\text { TNFRI } \\
\text { Tumour necrosis factor receptor } 1 \\
\text { Accession no. P25118 }\end{array}$ & $\begin{array}{l}\text { NPQ } \downarrow \text { DSGTAVL } \\
\text { PPLANVTNPQ } \\
\text { CMKLCLPPPL }\end{array}$ & MP, ADAM17 & $\begin{array}{l}\text { Mohan et al., } 2002 \\
\text { Pinckard et al., } 1997 \\
\text { Reddy et al., } 2000\end{array}$ \\
\hline $\begin{array}{l}\text { TNFRII } \\
\text { Tumour necrosis factor receptor } 2 \\
\text { Accession no. P25119 }\end{array}$ & $\begin{array}{l}\text { PTLSAIPRTL } \\
\text { APESPTLSAI }\end{array}$ & MP, ADAM17 & $\begin{array}{l}\text { Mohan et al., } 2002 \\
\text { Peschon et al., } 1998 \\
\text { Pinckard et al., } 1997 \\
\text { Reddy et al., } 2000\end{array}$ \\
\hline $\begin{array}{l}\text { TRANCE } \\
\text { TNF-related activation-induced } \\
\text { Cytokine } \\
\text { Accession no. } 035235\end{array}$ & VGP $\downarrow Q R F S G A P$ & ADAM17, 19, 33 & $\begin{array}{l}\text { Chesneau et al., } 2003 \\
\text { Lum et al., } 1999 \\
\text { Mohan et al., } 2002 \\
\text { Zou et al., } 2004\end{array}$ \\
\hline
\end{tabular}

Most sequences represent juxtamembraneous regions of the respective proteins. All peptide sequences were derived from the mouse proteins and their Swiss-Prot/TrEMBL database accession numbers are listed (http://www.expasy.org/sprot/). Arrows indicate the ADAM8 cleavage sites identified in this work by HPLC/mass spectrometry (except $\mathrm{a}, \mathrm{b}, \mathrm{c}$ ). References on cleavage of the homologous human peptides or respective membrane proteins are given in the right column. ClustalX was used to determine homologous mouse peptides. MP, undefined metalloprotease.

aData from Amour et al. (2002) from homologous human peptide sequences.

bData from Schlomann et al. (2002).

'Estimated cleavage site. 
A

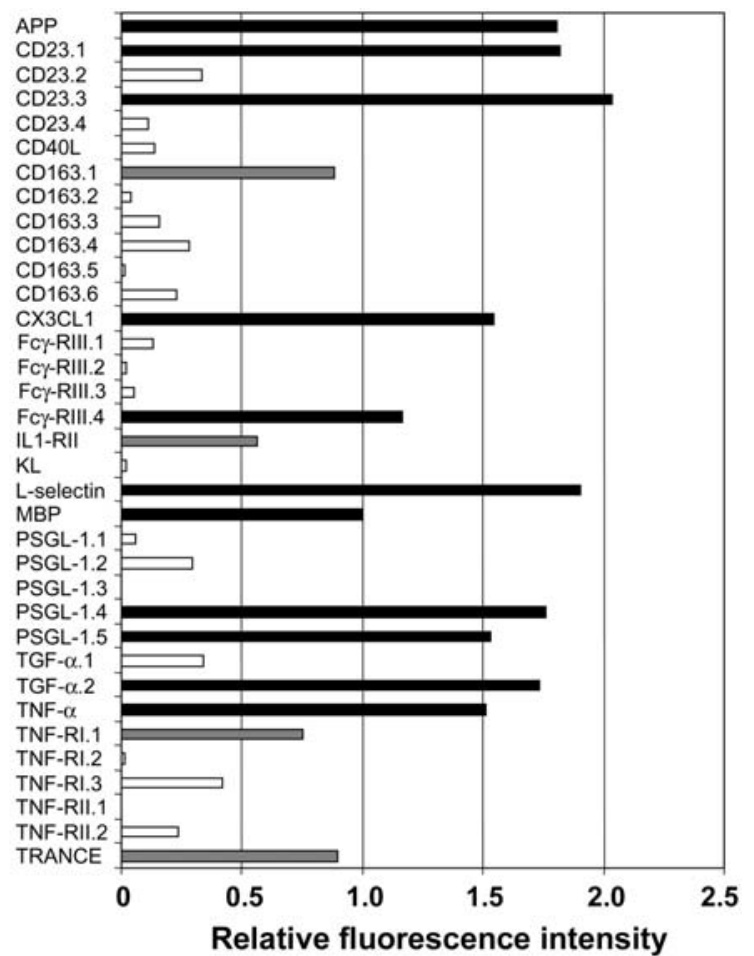

B

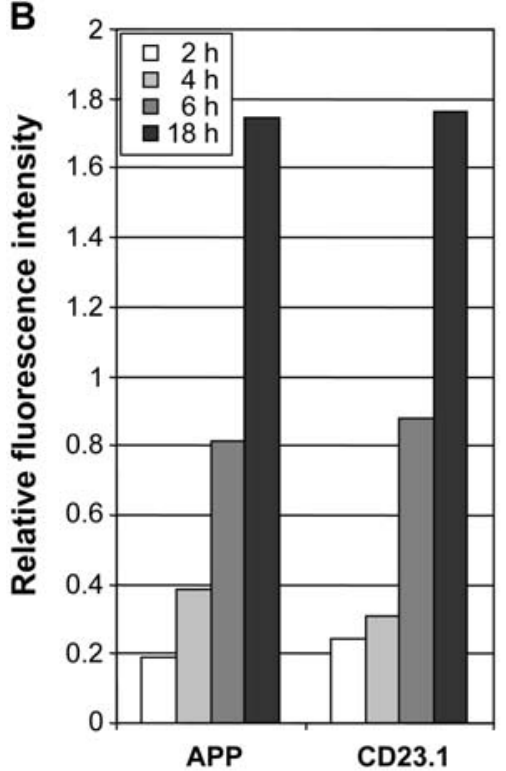

Figure 3 Peptide screening for potential ADAM8 substrates using the ProteaseSpot ${ }^{\mathrm{TM}}$ system.

Peptides selected and ADAM8 cleavage sites are listed in Table 1. (A) The fluorescence increase based on proteolytic release of the fluorophore was measured after $18 \mathrm{~h}$. Fluorescence values correspond to ADAM8 activity and are given as units normalised to the myelin basic protein (MBP) peptide set to 1. Fluorescence increase $\geq 1$ is assumed to indicate significant cleavage (black bars), and increases of $0.5-1$ (grey bars) indicate cleavage with lower efficiency. An increase $\leq 0.5$ (white bars) indicates no protease-substrate relationship. Cleavage analysis was performed with at least three independent ADAM8 preparations. Peptides derived from APP, CD23, fractalkine CX3CL1, FC $\varepsilon$-RIII, L-selectin, PSGL-1, TGF- $\alpha$ and TNF- $\alpha$ were cleaved significantly. (B) Time-dependent increase in fluorescence after 2, 4, 6 and $18 \mathrm{~h}$ of incubation of APP and CD23.1 peptides with ADAM8 protease. Values were corrected for the fluorescence values at $t=0$.

ADAM8 lacks prodomain removal and is catalytically inactive in transfection assays (Naus et al., 2004). Addi- tional controls were full-length ADAM10 and mock vector (Figure 5). In AP-APP cells, ADAM8 was expressed in the active full-length form (Figure 5B), with a 120-kDa band for pro-ADAM8, a 90-kDa band for processed ADAM8 and a band representing the remnant form of ADAM8 of ca. $60 \mathrm{kDa}$. In contrast, EQ-ADAM8 was not processed because of the lack of autocatalytic prodomain removal (Figure 5B; Schlomann et al., 2002). Compared to mock transfected cells, active full-length ADAM8, but not the inactive EQ-ADAM8, increased AP-APP shedding (Figure $5 A)$, revealing that ADAM8 is able to cleave APP in vivo. An identical result was observed by immunoblot analysis of the same supernatants (Figure 5B) using monoclonal antibody W02, which detects $\alpha$-secretase-cleaved APP (Ida et al., 1996). No significant changes in the amount of full-length APP in the cell lysate were detected. This shows that ADAM 8 acts as a true $\alpha$-secretase and cleaves APP within the $A \beta$ domain, which fits well with the in vitro cleavage site shown in Table 1.

Interestingly, ADAM8 stimulated APP release to an extent comparable to ADAM10 (Figure 5A), which is one of the candidate $\alpha$-secretases that cleave APP (Lammich et al., 1999). Thus, we have demonstrated that ADAM8 might contribute to $\alpha$-secretase activity in vivo.

\section{Discussion}

Active ADAM8 was isolated from $E$. coli because of its solubility and ability for autocatalytic prodomain removal. The rate of autocatalysis leading to active ADAM8, however, was variable for different preparations. A similar observation was made for ADAM8 expressed in COS cells. This might be because autocatalysis is less efficient with only the MP domain, whereas soluble ADAM8 containing the disintegrin/cysteine-rich domain is completely activated by prodomain removal (Schlomann et al., 2002), but would likely cause solubility problems in $E$. coli. In addition, in terms of inhibitory profile and substrate specificity, ADAM8 from E. coli is indistinguishable from soluble ADAM8 expressed in COS cells (Schlomann et al., 2002; Naus et al., 2004), suggesting that glycosylation of the ADAM8 protein in eukaryotes is not essential for catalytic activity. Similar to ADAM8 expressed in COS cells, catalytic activity of $E$. coli-expressed ADAM8 was inhibited by EDTA, ortho-phenanthroline, and BB-94, but not by marimastat (data not shown).

The ability of recombinant ADAM8 protease to cleave 10-mer peptides specifically was previously demonstrated (Amour et al., 2002), a prerequisite for screening new potential substrates of ADAM8 protease by the ProteaseSpot $^{\mathrm{TM}}$ method. When selecting the peptides, we considered that many ADAM substrates are cleaved in juxtamembraneous regions. In addition, species consistency was maintained by screening peptides derived from mouse membrane proteins with mouse ADAM8 protease. In the present work, peptides derived from APP, CD16, CD23, fractalkine CX3CL1, L-selectin, PSGL-1, TGF- $\alpha$, TNF- $\alpha$, CD163, IL-1-RII, TNFRI and TRANCE were significantly cleaved by ADAM8. Although it is difficult to transfer the peptide cleavage data to a physiological situation, we can draw some conclusions. In the 
A

$\begin{array}{lcccccccccccc}\text { position } & & \text { P5 } & \text { P4 } & \text { P3 } & \text { P2 } & \text { P1 } & \text { P1' } & \text { P2' } & \text { P3' } & \text { P4' } & \text { P5 ' } \\ \text { wildtype MBP } & \text { 1. } & \text { Y } & \text { G } & \text { S } & \text { L } & \text { P } & \downarrow \text { Q } & \text { K } & \text { A } & \text { Q } & \text { G } \\ & & & & & & & & & & & \\ \text { MBP variants } & \text { 2. } & \text { Y } & \text { G } & \text { L } & \text { L } & \text { P } & \text { Q } & \text { K } & \text { A } & \text { Q } & \text { G } \\ & \text { 3. } & \text { Y } & \text { G } & \text { S } & \text { L } & \text { R } & \text { Q } & \text { K } & \text { A } & \text { Q } & \text { G } \\ & \text { 4. } & \text { Y } & \text { G } & \text { S } & \text { L } & \text { K } & \text { Q } & \text { K } & \text { A } & \text { Q } & \text { G } \\ & \text { 5. } & \text { Y } & \text { G } & \text { S } & \text { L } & \text { P } & \text { E } & \text { K } & \text { A } & \text { Q } & \text { G } \\ & \text { 6. } & \text { Y } & \text { G } & \text { S } & \text { L } & \text { P } & \text { Q } & \text { E } & \text { A } & \text { Q } & \text { G } \\ & \text { 7. } & \text { Y } & \text { G } & \text { S } & \text { L } & \text { P } & \text { Q } & \text { V } & \text { A } & \text { Q } & \text { G } \\ & \text { 8. } & \text { Y } & \text { G } & \text { S } & \text { L } & \text { P } & \text { Q } & \text { K } & \text { T } & \text { Q } & \text { G }\end{array}$

B

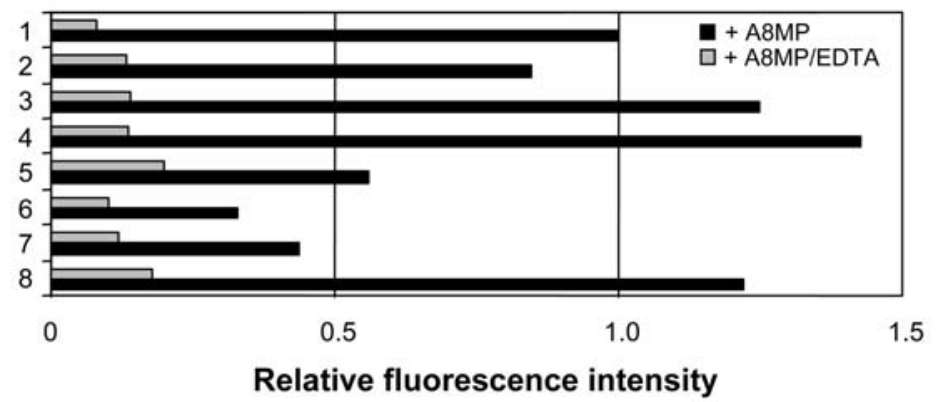

Figure 4 ADAM8-dependent cleavage of MBP peptide variants.

A peptide derived from the original MBP cleavage site and seven variant peptides were incubated with active ADAM8 protease. Amino acid variants are given in bold letters. Average fluorescence values for each peptide were determined after $18 \mathrm{~h}$. Values are given as units normalised to the fluorescence increase for the original MBP peptide set to 1 . The peptides with amino acid variations in positions $\mathrm{P}^{\prime}$ ' and $\mathrm{P} 2$ ' were cleaved at significantly lower levels.

case of APP and TGF- $\alpha$, ADAM8 cleavage sites match with the reported sites. For CD16, as deduced from the molecular mass of the released fragment reported (Harrison et al., 1991), cleavage occurs in the most membrane-proximal region. CD23 peptide cleavage sites of ADAM8 match with those reported earlier from in vivo cleavage (Mayer et al., 2002). Cleavage of L-selectin, TGF- $\alpha$, TNF- $\alpha$ and TNFRI occurs at cleavage sites slightly ( \pm 1 or 2 amino acids) different from the physiological sites (see references in Table 1), but sequences used for the screening were derived from mouse sequences, whereas most of the reported sequences refer to human sequences, which have significant differences. For peptides representing CD23 (SNQLAQ $\downarrow$ K $\downarrow$ SQV) and TGF- $\alpha$ (AVVAASQ $\downarrow K \downarrow K Q$ ), ADAM8 cleavage was observed at two adjacent amino acid residues, suggesting that ADAM8 recognises the peptide, but cleaves with inaccuracy.

Peptides derived from the cleavage site of MBP with amino acid exchanges in positions $\mathrm{P} 3-\mathrm{P}^{\prime}$ ' were cleaved by ADAM8 with different efficiencies. Assuming that cleavage occurred at the same sites in all peptides, it could be concluded for the MBP peptide that ADAM8 preferred a cleavage site with basic residues in positions P1 and/or P2' and one without acidic residues around the cleavage site, substantially not in position $\mathrm{P}^{\prime}$ and P2'. Mayer et al. (2002) suggested a similar hypothetical consensus sequence $\mathrm{XXR/K} \downarrow \mathrm{XKX}$ from human CD23 cleavage sites. A motif with QK at positions $\mathrm{P} 1^{\prime}$ and $\mathrm{P} 2$ ' in the peptides derived from APP, CD23 and MBP was also present in the TGF- $\alpha$ peptide (AVVAASQ $\downarrow K \downarrow K Q$ ), suggesting physiological cleavage next to this motif. Examination of the screened peptide collection revealed regularity for cleaved peptides that were not applicable for most of the non-cleaved peptides. The cleaved pep- tides contained basic amino acid residues, whereas they did not contain cysteine, methionine or tryptophan residues. Only five of the cleaved peptides (APP, IL-1-RII, Lselectin, PSGL-1, TNFRI) contained acidic residues, and only in the peptides representing IL-1-RII and TNFRI were these acidic residues located in positions P3-P3' of proposed or determined cleavage sites.

Despite these regularities, ADAM substrate cleavage sites are often promiscuous. In peptides derived from TNF- $\alpha$, three different cleavage sites for ADAM8, and two different cleavage sites for ADAM9 and ADAM19, respectively, were determined (Roghani et al., 1999; Amour et al., 2002; Chesneau et al., 2003; Fourie et al., 2003). Three different cleavage sites were sequenced for ADAM9 in a $\mathrm{KL}$ peptide (Amour et al., 2002). The MBP cleavage next to the QK motif was determined for ADAM8, ADAM10 and ADAM28, emphasising the importance of this motif (Howard et al., 2001; Schlomann et al., 2002). ADAM8, ADAM9 and ADAM33 cleaved an APP peptide also at the QK motif, whereas ADAM10 and ADAM17 cleaved the APP peptide two amino acids closer to the C-terminus (Roghani et al., 1999; Amour et al., 2002; Mohan et al., 2002; Zou et al., 2004). Comparison of different substrate peptides also shows that different ADAMs cleave the same substrate peptides, with the cleavage sites being the same or in close proximity. This could indicate that ADAM catalytic activities towards peptides are similar, although kinetic properties could be different. Further studies are necessary to determine substrate specificity of ADAMs; however, based on our analysis, the likelihood of peptide cleavage by ADAM8 can be predicted.

Based on cleavage of the APP protein by ADAM8, we have in vivo evidence for ADAM 8 as additional $\alpha$-secretase activity. APP is cleaved proteolytically in two distinct 
A

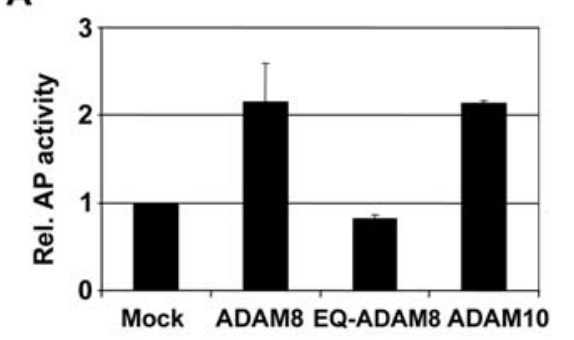

B

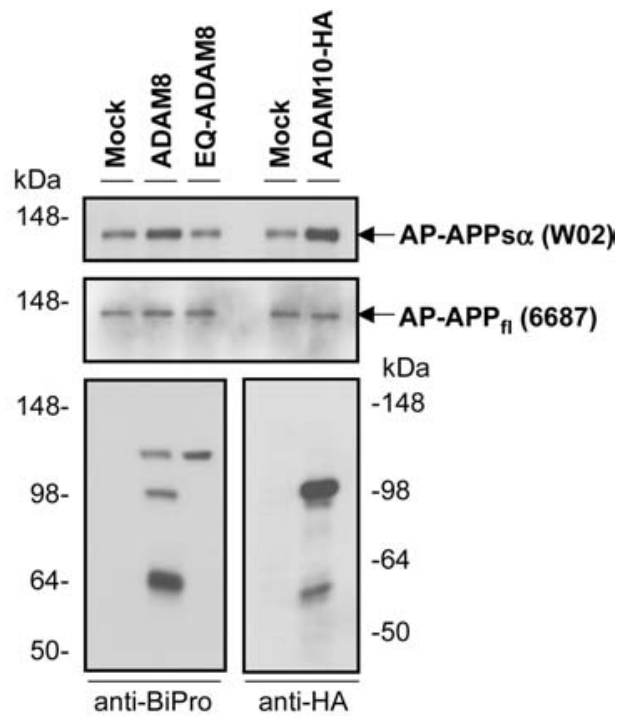

Figure 5 Shedding of APP by ADAM8 in 293 cells expressing alkaline phosphatase (AP)-tagged APP (AP-APP cells).

Cells were transiently transfected with plasmids encoding ADAM8 or ADAM10. As controls, cells were transfected with mock vector (pTarget for the ADAM8 constructs and peak12 for the ADAM10 construct) or with inactive ADAM8 (EQ-ADAM8). (A) Quantification of AP-APP released into the conditioned medium relative to mock transfected cells. The mean and standard deviation of two independent experiments are reported, each one carried out in duplicate. (B) Western blot analysis confirming the increase in AP-APP shedding upon transfection of ADAM8 and demonstrating the presence of processed ADAM8 protein: $120 \mathrm{kDa}$, pro-ADAM8; $90 \mathrm{kDa}$, processed ADAM8 lacking the prodomain; and $60 \mathrm{kDa}$, ADAM8 lacking the pro- and metalloprotease domain. In contrast, inactive EQ-ADAM8 is only present in its proform. ADAM10-HA can also be detected in its immature (upper band) and mature (lower band) forms. For detection of the different proteins, the indicated antibodies were used. AP-APPs $\alpha$, soluble AP-APP generated by $\alpha$-secretase; AP-APP $f$, full-length AP-APP; anti-HA, antibody against the Cterminal HA-epitope tag of ADAM10; anti-BiPro, antibody against the C-terminal BiPro-epitope tag of ADAM8.

pathways. In the amyloidogenic pathway, APP is cleaved by $\beta$ - and $\gamma$-secretases to release amyloid $\beta(A \beta)$ peptide, which forms non-soluble plaques (Haass, 2004). In the anti-amyloidogenic pathway, APP is cleaved within the amyloidogenic $A \beta$ domain by $\alpha$-secretase to release a non-amyloidogenic p3 peptide and, furthermore, a large ectodomain of APP (APPs $\alpha$ ) with neuroprotective and memory-enhancing function (Furukawa et al., 1996; Meziane et al., 1998; Mattson et al., 1999).

ADAM9, 10 and 17 are known as $\alpha$-secretases and cleave APP into non-amyloidogenic forms (Buxbaum et al., 1998; Koike et al., 1999; Lammich et al., 1999), preventing accumulation of amyloidogenic $A \beta$ peptides to cerebral plaques that cause Alzheimer's disease. In addi- tion, ADAM8 and ADAM33 were shown to cleave a peptide derived from the $\alpha$-secretase cleavage site (Amour et al., 2002; Zou et al., 2004). However, in co-transfection experiments, ADAM33 did not cleave APP, but acted as a negative regulator of APP shedding (Zou et al., 2004). Moreover, no difference in the production of APP cleavage products in cultured hippocampal neurons from ADAM9-deficient mice was detected compared to wildtype neurons, arguing against an important role of ADAM9 as $\alpha$-secretase (Weskamp et al., 2002). However, mice slightly overexpressing ADAM10 produced more neurotrophic APPs and lower amounts of amyloidogenic $A \beta$ peptides, suggesting that activation of ADAM10 $\alpha$-secretase activity might be a therapeutic target for treatment of Alzheimer's disease (Postina et al., 2004). Possibly, endogenous $\alpha$-secretase activity is composed of several ADAM enzymes (Asai et al., 2003). The upregulation of ADAM8 expression in the nervous system under inflammatory conditions supports the hypothesis that ADAM8 belongs to this set of $\alpha$-secretases (Schlomann et al., 2000). ADAM8 might contribute to enhanced production of neuroprotective APPs under pathological conditions to compensate for neurodegeneration as an additional $\alpha$-secretase in the CNS during inflammation. Taken together, our peptide analyses demonstrate that a systematic ADAM substrate search should be based on three criteria: (i) peptides are of sufficient length to represent the physiological cleavage sites of the substrates; (ii) ADAMs cleave the peptide at a physiologically important site; and (iii) the full-length protein is cleaved in the same manner. Providing complete proof for the last criterion will be the subject of further studies.

\section{Materials and methods}

\section{Expression of soluble ADAM8 protease in E. coli and purification}

For ADAM8 expression in bacteria, the vector pASK-IBA3+ (IBA, Göttingen, Germany) was used. This vector encodes a Strep$\operatorname{tag}^{\circledR}$ that allows purification of the expressed protein by StrepTactin ${ }^{\circledR}$ MacroPrep ${ }^{\circledR}$ Cartridges (IBA). The cDNA encoding the mouse ADAM8 pro- and metalloprotease domain was amplified with primers mA8_EcoRI.s 5'-GAA TTC CTT GGC CTC TGG CTG CTC AGC-3' and mA8_Xhol.as 5'-CTC GAG GAT CTC CTG AGG CTT AAA CTG AGG GAA GGA CAC GAA CCG GTT GAC ATC TGG-3' containing the sequence for the BiPro-tag at the $3^{\prime}$ end. The resulting CDNA was cloned into the respective restriction sites of PASK-IBA3+ and transformed into E. coli strain BL21(DE3)pLysS. Bacteria were grown in the presence of tetracycline and ampicillin. For protein expression, bacteria were grown in LB medium and induced at $\mathrm{OD}_{550} 0.5$ with $0.2 \mu \mathrm{g} / \mathrm{ml}$ anhydrotetracycline (aTc, IBA) for $6 \mathrm{~h}$ at $30^{\circ} \mathrm{C}$ with $50 \mu \mathrm{M} \mathrm{ZnCl}$ added to the medium. After harvesting the bacteria, pellets were resuspended in $100 \mathrm{~mm}$ Tris, $\mathrm{pH} 8.0,150 \mathrm{~mm} \mathrm{NaCl}$ containing $1 \mathrm{~mm}$ phenylmethylsulfonyl fluoride and sonicated, and $5 \mu \mathrm{g} / \mathrm{ml}$ DNase I and $10 \mathrm{mg} / \mathrm{ml}$ Rnase A were added. The mixture was centrifuged twice at $13000 \mathrm{~g}$ and once at $150000 \mathrm{~g}$ before applying the supernatants to Strep-Tactin ${ }^{\circledR}$ cartridges and FPLC. The purity of soluble ADAM8 was confirmed by SDS-PAGE and protein concentrations were determined using BCA reagent (Pierce, Heidelberg, Germany). Depending on the amount of purified protein, FPLC eluates were concentrated with Amicon Ultra Centrifugal Filter Units (Millipore, Bedford, MA, USA). Pro- 
teolytic activity was monitored using a fluorescent cleavage assay with the peptide DNP-SHHGDQMAQKSQSTQI in the absence or presence of ADAM inhibitors.

\section{Protease assays}

The ProteaseSpot ${ }^{\mathrm{TM}}$ system is based on peptides synthesised on continuous cellulose membranes (JPT Peptide Technologies $\mathrm{GmbH}$, Berlin, Germany). Cellulose disks were cut into equivalent pieces, activated in methanol for $5 \mathrm{~min}$ and subsequently washed four times with HEPES buffer (20 mM HEPES, pH 7.4, $0.015 \%$ Brij-35). For the reactions, disks were incubated at $37^{\circ} \mathrm{C}$ with $100 \mu \mathrm{l}$ of protease solution containing $50-100 \mathrm{ng}$ of ADAM8 protease, complete EDTA-free protease inhibitor cocktail (Roche Applied Science, Mannheim, Germany) and HEPES buffer. For negative controls, $10 \mathrm{~mm}$ EDTA was added to the samples. For positive controls, some peptides containing arginine or lysine residues were incubated with a $0.1 \%(\mathrm{w} / \mathrm{v})$ solution of trypsin (Roche Applied Science).

Fluorescence (excitation at $325 \mathrm{~nm}$ and emission at $420 \mathrm{~nm}$ ) was measured initially, after 2, 4 and $6 \mathrm{~h}$, and after $18 \mathrm{~h}$ using a Perkin-Elmer LS50B luminescence spectrometer in blackcoated 96-well plates (Nunc, Wiesbaden, Germany).

Protease assays in solution were performed to analyse the catalytic activity of purified ADAM8. The peptide DNPSHHGDQMAQKSQSTQI $(100 \mu \mathrm{M})$ was incubated with $100 \mu$ l of protease solution containing 50-100 ng of ADAM8 protease, Complete EDTA-free protease inhibitor cocktail (Roche Applied Science) and HEPES buffer (20 mM HEPES, pH 7.4, 0.015\% Brij35), with $10 \mathrm{~mm}$ EDTA added to the negative controls. Immediately, and after 2 and $4 \mathrm{~h}$ of incubation, $30 \mu \mathrm{l}$ samples were mixed with $65 \mu$ l of HEPES buffer and $5 \mu$ l of $1 \%$ fluorescamine (Sigma, Taufkirchen, Germany). Fluorescence (excitation at $386 \mathrm{~nm}$ and emission at $477 \mathrm{~nm}$ ) was measured with a PerkinElmer LS50B luminescence spectrometer in black-coated 96well plates (Nunc).

\section{Western blot analysis}

For Western blot sample preparation, total bacterial lysate pellets with equal cell amounts were mixed with $1 \times$ SDS sample buffer and sonicated. For inclusion body samples, the pellets were resuspended in $100 \mathrm{~mm}$ Tris, $\mathrm{pH} 8.0,150 \mathrm{~mm} \mathrm{NaCl}$. All protein samples were mixed with $5 \times$ SDS sample buffer $(50 \%$ glycerol, $10 \%$ SDS, $100 \mathrm{~mm} \beta$-mercaptoethanol, $0.05 \%$ bromophenol blue in $250 \mathrm{~mm}$ Tris- $\mathrm{HCl}, \mathrm{pH}$ 6.8), boiled for $10 \mathrm{~min}$ and loaded onto $12.5 \%$ SDS-PAGE for soluble ADAM8 detection and $7.5 \%$ SDS-PAGE for full-length ADAM8. After gel runs, the proteins were blotted onto nitrocellulose transfer membranes (Protran ${ }^{\circledR}$ BA79, $0.1 \mu \mathrm{m}$ pore size, Schleicher \& Schuell, Dassel, Germany) by semidry electroblotting. After control staining with $0.1 \%$ Ponceau S solution and blocking for $2 \mathrm{~h}$ with $5 \%$ skim milk in TBS containing $0.1 \%$ Tween-20, proteins were analysed by immunostaining. Mouse monoclonal anti-BiPro-tag antibody (kindly provided by Dr. B.M. Jockusch, Braunschweig, Germany) was diluted 1:25 in blocking buffer and incubated with the membranes overnight at $4^{\circ} \mathrm{C}$. The detection of proteins was performed with anti-mouse-lgG-horseradish peroxidase (1:8000, $1 \mathrm{~h}$ at RT, Sigma) using Lumi-LightPLUS (Roche Applied Science) as the chemiluminescent substrate. Kodak X-OMAT X-ray films were exposed to the emitted light. Exposure times depended on the intensity of the reaction. Fixing and developing of the films was performed with Kodak X-ray Developer LX 24 and Kodak X-ray Fixer AL4 (Eastman Kodak, Rochester, NY, USA).

For immunoblot detection of the different AP-APP species and ADAM8 and ADAM10 expression in AP-APP cell lysates and conditioned medium, aliquots of the conditioned medium and cell lysates were boiled for 5 min at $95^{\circ} \mathrm{C}$ with SDS sample buf- fer. The samples were subjected to SDS-PAGE on an $8 \%$ SDS gel. Proteins were transferred to a PVDF membrane and detected with the following antibodies: mouse monoclonal antibody W02 against AP-APPs $\alpha$ (kind gift of K. Beyreuther; directed against amino acids $1-16$ of the $A \beta$ sequence; Ida et al., 1996); polyclonal antibody 6687 against the C-terminus of APP detecting full-length APP (Steiner et al., 2000); and antibody anti-BiPro, detecting the C-terminal BiPro epitope tag of ADAM8 and EQADAM8. For detection of ADAM10-HA expression, the 6687-blot was stripped and reprobed with a polyclonal anti-HA antibody (Sigma).

\section{Determination of peptide cleavage sites by mass spectrometry}

Peptide substrate $(100 \mu \mathrm{M})$ in $250 \mu$ l of buffer containing $25 \mathrm{~mm}$ Tris, pH 8.0 and $0.0006 \%$ Brij-35 was incubated with $300 \mathrm{ng}$ of ADAM8 metalloprotease domain isolated from a Strep-Tactin ${ }^{\circledR}$ affinity column. Incubations were performed at room temperature or $37^{\circ} \mathrm{C}$ for $4 \mathrm{~h}$, after which an equal volume of $1 \%$ heptafluorobutyric acid (HFBA) was added. Substrate was separated from product by separation on a $\mathrm{C} 18$ column from Vydac (Hesperia, CA, USA) using an acetonitrile/water gradient with $0.1 \%$ HFBA. Further purification was performed using a Shimadzu LC system (comprising a solvent degasser, two LC$10 A$ pumps and a SCL-10A system controller). The LC was coupled to a QSTAR XL quadrupole time-of-flight tandem mass spectrometer (ABI/MDS-Sciex, Toronto, Canada) equipped with an electrospray source. LC was operated at a flow rate of $200 \mu \mathrm{l} / \mathrm{min}$ with a linear gradient as follows: $100 \% \mathrm{~A}$ held isocratically for $2 \mathrm{~min}$, linearly increased to $60 \%$ B over $18 \mathrm{~min}$ and then increased to $100 \%$ B over 5 min. Mobile phase A consisted of water/acetonitrile $(98: 2 \mathrm{v} / \mathrm{v})$ with $0.1 \%$ acetic acid and mobile phase B of acetonitrile/water $(90: 10 \mathrm{v} / \mathrm{v})$ with $0.1 \%$ acetic acid. A Zorbax C8 reverse-phase column $(2.1 \times 50 \mathrm{~mm})$ was used for all LC-MS analyses. MS data acquisition and analysis were performed using the Analyst QS software.

\section{Cell culture and transfections}

Clonal 293-EBNA cells expressing AP-APP and Bcl-X/CrmA (clone SABC70) were generated and cultured as described by Schöbel et al. (2006). Transfections were carried out using Lipofectamine 2000 (Invitrogen, Groningen, Netherlands). The medium was replaced with fresh medium 1 day after transfection. After overnight incubation, conditioned medium and cell lysate (in $50 \mathrm{~mm}$ Tris, $\mathrm{pH} 7.5,150 \mathrm{~mm} \mathrm{NaCl}, 1 \%$ Nonidet-P 40) were collected. Aliquots of the conditioned medium were treated for $30 \mathrm{~min}$ at $65^{\circ} \mathrm{C}$ to heat-inactivate the endogenous AP activity. AP activity in the conditioned medium was measured as previously described (Lichtenthaler et al., 2003) and normalised to the protein concentration in the cell lysate. The cDNA encoding C-terminally HA-epitope tagged ADAM10 was cloned into the expression vector peak12.

\section{Acknowledgements}

We thank Dr. O. Kruse, Bielefeld University, for help with fluorescence analysis, Dr. H. Tschesche, Bielefeld University, for the kind gift of BB-94, Dr. B.M. Jockusch, Braunschweig University, for providing BiPro antibody, Dr. K. Beyreuther, Heidelberg University, for providing W02 antibody, and C. Haass for antibody 6687. This work was supported by the Deutsche Forschungsgemeinschaft (BA1606/2-1 to J.W.B. and SFB596-B12 to S.F.L.) and by the Ministry of Education and Science Northrhine-Westphalia, Graduate School for Bioinformatics and Genome Research (grant to S.N.). 


\section{References}

Amour, A., Knight, C.G., Webster, A., Slocombe, P.M., Stephens, P.E., Knäuper, V., Docherty, A.J., and Murphy, G. (2000). The in vitro activity of ADAM-10 is inhibited by TIMP-1 and TIMP3. FEBS Lett. 473, 275-279.

Amour, A., Knight, C.G., English, W.R., Webster, A., Slocombe, P.M., Knäuper, V., Docherty, A.J., Becherer, J.D., Blobel, C.P., and Murphy, G. (2002). The enzymatic activity of ADAM8 and ADAM9 is not regulated by TIMPs. FEBS Lett. 524, 154-155.

Arribas, J., Lopez-Casillas, F., and Massague, J. (1997). Role of the juxtamembrane domains of the transforming growth factor- $\alpha$ precursor and the $\beta$-amyloid precursor protein in regulated ectodomain shedding. J. Biol. Chem. 272, 17160-17165.

Asai, M., Hattori, C., Szabo, B., Sasagawa, N., Maruyama, K., Tanuma, S., and Ishiura, S. (2003). Putative function of ADAM9, ADAM10, and ADAM17 as APP $\alpha$-secretase. Biochem. Biophys. Res. Commun. 301, 231-235.

Black, R.A., Rauch, C.T., Kozlosky, C.J., Peschon, J.J., Slack, J.L., Wolfson, M.F., Castner, B.J., Stocking, K.L., Reddy, P., Srinivasan, S., et al. (1997). A metalloproteinase disintegrin that releases tumour-necrosis factor- $\alpha$ from cells. Nature 385, 729-733.

Blobel, C.P. (2005). ADAMs: key components in EGFR signalling and development. Nat. Rev. Mol. Cell Biol. 6, 32-43.

Buxbaum, J.D., Liu, K.N., Luo, Y., Slack, J.L., Stocking, K.L., Peschon, J.J., Johnson, R.S., Castner, B.J., Cerretti, D.P., and Black, R.A. (1998). Evidence that tumor necrosis factor$\alpha$ converting enzyme is involved in regulated $\alpha$-secretase cleavage of the Alzheimer amyloid protein precursor. J. Biol. Chem. 273, 27765-27767.

Chantry, A., Gregson, N.A., and Glynn, P. (1989). A novel metalloproteinase associated with brain myelin membranes. Isolation and characterization. J. Biol. Chem. 264, 2160321607.

Chesneau, V., Becherer, J.D., Zheng, Y., Erdjument-Bromage, H., Tempst, P., and Blobel, C.P. (2003). Catalytic properties of ADAM19. J. Biol. Chem. 278, 22331-22340.

Davenpeck, K.L., Brummet, M.E., Hudson, S.A., Mayer, R.J., and Bochner, B.S. (2000). Activation of human leukocytes reduces surface P-selectin glycoprotein ligand-1 (PSGL-1, CD162) and adhesion to P-selectin in vitro. J. Immunol. 165, 2764-2772.

Droste, A., Sorg, C., and Hogger, P. (1999). Shedding of CD163, a novel regulatory mechanism for a member of the scavenger receptor cysteine-rich family. Biochem. Biophys. Res. Commun. 256, 110-113.

Fourie, A.M., Coles, F., Moreno, V., and Karlsson, L. (2003). Catalytic activity of ADAM8, ADAM15, and MDC-L (ADAM28) on synthetic peptide substrates and in ectodomain cleavage of CD23. J. Biol. Chem. 278, 30469-30477.

Furukawa, K., Sopher, B.L., Rydel, R.E., Begley, J.G., Pham, D.G., Martin, G.M., Fox, M., and Mattson, M.P. (1996). Increased activity-regulating and neuroprotective efficacy of $\alpha$-secretase-derived secreted amyloid precursor protein conferred by a C-terminal heparin-binding domain. J. Neurochem. 67, 1882-1896.

Garton, K.J., Gough, P.J., Blobel, C.P., Murphy, G., Greaves, D.R., Dempsey, P.J., and Raines, E.W. (2001). Tumor necrosis factor- $\alpha$-converting enzyme (ADAM17) mediates the cleavage and shedding of fractalkine (CX3CL1). J. Biol. Chem. 276, 37993-38001.

Haass, C. (2004). Take five - BACE and the $\gamma$-secretase quartet conduct Alzheimer's amyloid $\beta$-peptide generation. EMBO J. 23, 483-488.

Harrison, D., Phillips, J.H., and Lanier, L.L. (1991). Involvement of a metalloprotease in spontaneous and phorbol esterinduced release of natural killer cell-associated Fc $\gamma$ RIII (CD16-II). J. Immunol. 147, 3459-3465.
Howard, L., Zheng, Y., Horrocks, M., Maciewicz, R.A., and Blobel, C. (2001). Catalytic activity of ADAM28. FEBS Lett. 498, 82-86.

Ida, N., Hartmann, T., Pantel, J., Schröder, J., Zerfass, R., Förstl, H., Sandbrink, R., Masters, C.L., and Beyreuther, K. (1996). Analysis of heterogeneous $\beta A 4$ peptides in human cerebral spinal fluid and blood by a newly developed sensitive western blot assay. J. Biol. Chem. 271, 22908-22914.

Ishikawa, N., Daigo, Y., Yasui, W., Inai, K., Nishimura, H., Tsuchiya, E., Kohno, N., and Nakamura, Y. (2004). ADAM8 as a novel serological and histochemical marker for lung cancer. Clin. Cancer Res. 10, 8363-8370.

Kelly, K., Hutchinson, G., Nebenius-Oosthuizen, D., Smith, A.J., Bartsch, J.W., Horiuchi, K., Rittger, A., Manova, K., Docherty, A.J., and Blobel, C.P. (2005). Metalloprotease-disintegrin ADAM8: expression analysis and targeted deletion in mice. Dev. Dyn. 232, 221-231.

King, N.E., Zimmermann, N., Pope, S.M., Fulkerson, P.C., Nikolaidis, N.M., Mishra, A., Witte, D.P., and Rothenberg, M.E. (2004). Expression and regulation of a disintegrin and metalloproteinase (ADAM) 8 in experimental asthma. Am. J. Respir. Cell Mol. Biol. 31, 257-265.

Koike, H., Tomioka, S., Sorimachi, H., Saido, T.C., Maruyama, K., Okuyama, A., Fujisawa-Sehara, A., Ohno, S., Suzuki, K., and Ishiura, S. (1999). Membrane-anchored metalloprotease MDC9 has an $\alpha$-secretase activity responsible for processing the amyloid precursor protein. Biochem. J. 343, 371-375.

Lammich, S., Kojro, E., Postina, R., Gilbert, S., Pfeiffer, R., Jasionowski, M., Haass, C., and Fahrenholz, F. (1999). Constitutive and regulated $\alpha$-secretase cleavage of Alzheimer's amyloid precursor protein by a disintegrin metalloprotease. Proc. Natl. Acad. Sci. USA 96, 3922-3927.

Lichtenthaler, S.F., Dominguez, D.I., Westmeyer, G.G., Reiss, K., Haass, C., Saftig, P., De Strooper, B., and Seed, B. (2003). The cell adhesion protein P-selectin glycoprotein ligand-1 is a substrate for the aspartyl protease BACE1. J. Biol. Chem. 278, 48713-48719.

Lum, L., Wong, B.R., Josien, R., Becherer, J.D., Erdjument-Bromage, H., Schlondorff, J., Tempst, P., Choi, Y., and Blobel, C.P. (1999). Evidence for a role of a tumor necrosis factor- $\alpha$ (TNF- $\alpha$ )-converting enzyme-like protease in shedding of TRANCE, a TNF family member involved in osteoclastogenesis and dendritic cell survival. J. Biol. Chem. 274, 13613-13618.

Marolewski, A.E., Buckle, D.R., Christie, G., Earnshaw, D.L., Flamberg, P.L., Marshall, L.A., Smith, D.G., and Mayer, R.J. (1998). CD23 (Fc\&RII) release from cell membranes is mediated by a membrane-bound metalloprotease. Biochem. J. 333, 573-579.

Mattson, M.P., Pedersen, W.A., Duan, W., Culmsee, C., and Camandola, S. (1999). Cellular and molecular mechanisms underlying perturbed energy metabolism and neuronal degeneration in Alzheimer's and Parkinson's diseases. Ann. N.Y. Acad. Sci. 893, 154-175.

Mayer, R.J., Flamberg, P.L., Katchur, S.R., Bolognese, B.J., Smith, D.G., Marolewski, A.E., Marshall, L.A., and Faller, A. (2002). CD23 shedding: requirements for substrate recognition and inhibition by dipeptide hydroxamic acids. Inflamm. Res. 51, 85-90.

Meziane, H., Dodart, J.C., Mathis, C., Little, S., Clemens, J., Paul, S.M., and Ungerer, A. (1998). Memory-enhancing effects of secreted forms of the $\beta$-amyloid precursor protein in normal and amnestic mice. Proc. Natl. Acad. Sci. USA 95, 12683-12688.

Mohan, M.J., Seaton, T., Mitchell, J., Howe, A., Blackburn, K., Burkhart, W., Moyer, M., Patel, I., Waitt, G.M., Becherer, J.D., Moss, M.L., and Milla, M.E. (2002). The tumor necrosis factor- $\alpha$ converting enzyme (TACE): a unique metalloproteinase with highly defined substrate selectivity. Biochemistry 41 , 9462-9469. 
Moss, M.L. and Bartsch, J.W. (2004). Therapeutic benefits from targeting of ADAM family members. Biochemistry 43, 7227-7235.

Moss, M.L., Jin, S.L., Milla, M.E., Bickett, D.M., Burkhart, W., Carter, H.L., Chen, W.J., Clay, W.C., Didsbury, J.R., Hassler, D., et al. (1997). Cloning of a disintegrin metalloproteinase that processes precursor tumour-necrosis factor- $\alpha$. Nature 385, 733-736.

Naus, S., Richter, M., Wildeboer, D., Moss, M., Schachner, M., and Bartsch, J.W. (2004). Ectodomain shedding of the neural recognition molecule $\mathrm{CHL} 1$ by the metalloprotease-disintegrin ADAM8 promotes neurite outgrowth and suppresses neuronal cell death. J. Biol. Chem. 279, 16083-16090.

Peschon, J.J., Slack, J.L., Reddy, P., Stocking, K.L., Sunnarborg, S.W., Lee, D.C., Russell, W.E., Castner, B.J., Johnson, R.S., Fitzner, J.N., et al. (1998). An essential role for ectodomain shedding in mammalian development. Science 282, 1281-1284.

Pinckard, J.K., Sheehan, K.C., Arthur, C.D., and Schreiber, R.D. (1997). Constitutive shedding of both p55 and p75 murine TNF receptors in vivo. J. Immunol. 158, 3869-3873.

Postina, R., Schroeder, A., Dewachter, I., Bohl, J., Schmitt, U., Kojro, E., Prinzen, C., Endres, K., Hiemke, C., Blessing, M., et al. (2004). A disintegrin-metalloproteinase prevents amyloid plaque formation and hippocampal defects in an Alzheimer disease mouse model. J. Clin. Invest. 113, 1456-1464.

Reddy, P., Slack, J.L., Davis, R., Cerretti, D.P., Kozlosky, C.J., Blanton, R.A., Shows, D., Peschon, J.J., and Black, R.A. (2000). Functional analysis of the domain structure of tumor necrosis factor- $\alpha$ converting enzyme. J. Biol. Chem. 275, 14608-14614.

Roemer, A., Schwettmann, L., Jung, M., Roigas, J., Kristiansen, G., Schnorr, D., Loening, S.A., Jung, K., and Lichtinghagen, R. (2004). Increased mRNA expression of ADAMs in renal cell carcinoma and their association with clinical outcome. Oncol. Rep. 11, 529-536.

Roghani, M., Becherer, J.D., Moss, M.L., Atherton, R.E., Erdjument-Bromage, H., Arribas, J., Blackburn, R.K., Weskamp, G., Tempst, P., and Blobel, C.P. (1999). Metalloprotease- disintegrin MDC9: intracellular maturation and catalytic activity. J. Biol. Chem. 274, 3531-3540.

Schlomann, U., Rathke-Hartlieb, S., Yamamoto, S., Jockusch, H., and Bartsch, J.W. (2000). Tumor necrosis factor- $\alpha$ induces a metalloprotease-disintegrin, ADAM8 (CD 156): implications for neuron-glia interactions during neurodegeneration. J. Neurosci. 20, 7964-7971.

Schlomann, U., Wildeboer, D., Webster, A., Antropova, O. Zeuschner, D., Knight, C.G., Docherty, A.J., Lambert, M., Skelton, L., Jockusch, H., and Bartsch, J.W. (2002). The metalloprotease disintegrin ADAM8. Processing by autocatalysis is required for proteolytic activity and cell adhesion. J. Biol. Chem. 277, 48210-48219.

Schöbel, S., Neumann, S., Seed, B., and Lichtenthaler, S.F. (2006). Expression cloning screen for modifiers of amyloid precursor protein shedding. Int. J. Dev. Neurosci., in press.

Seals, D.F. and Courtneidge, S.A. (2003). The ADAMs family of metalloproteases: multidomain proteins with multiple functions. Genes Dev. 17, 7-30.

Steiner, H., Kostka, M., Romig, H., Basset, G., Pesold, B., Hardy, J., Capell, A., Meyn, L., Grim, M.L., Baumeister, R., et al. (2000). Glycine 384 is required for presenilin-1 function and is conserved in bacterial polytopic aspartyl proteases. Nat. Cell Biol. 2, 848-851.

Weskamp, G., Cai, H., Brodie, T.A., Higashiyama, S., Manova, K., Ludwig, T., and Blobel, C.P. (2002). Mice lacking the metalloprotease-disintegrin MDC9 (ADAM9) have no evident major abnormalities during development or adult life. Mol. Cell. Biol. 22, 1537-1544.

Yoshida, S., Setoguchi, M., Higuchi, Y., Akizuki, S., and Yamamoto, S. (1990). Molecular cloning of cDNA encoding MS2 antigen, a novel cell surface antigen strongly expressed in murine monocytic lineage. Int. Immunol. 2, 585-591.

Zou, J., Zhu, F., Liu, J., Wang, W., Zhang, R., Garlisi, C.G., Liu, Y.H., Wang, S., Shah, H., Wan, Y., and Umland, S.P. (2004). Catalytic activity of human ADAM33. J. Biol. Chem. 279, 9818-9830.

Received October 24, 2005; accepted December 14, 2005 